International Journal of Electrical and Power Engineering 4 (4): 209-217, 2010

ISSN: 1990-7958

(C) Medwell Journals, 2010

\title{
Intelligent Controller Based Shunt Active Filter for Power Quality Improvement of Matrix Converter
}

\author{
P. JenoPaul, I. Jacob Raglend and T. Ruban Deva Prakash \\ Noorul Islam University, Electrical and Electronics Engineering, Tamilnadu, India
}

\begin{abstract}
This study proposes a Hysteresis Fuzzy Logic Controlled (H-FLC) based shunt active filter to minimize the power quality impact instead of using the conventional fixed filters and active filters of the matrix converters. Matrix converters inject significant harmonics and nonstandard frequency components into power systems. The proposed approach eliminates the total line current harmonics efficiently. By minimizing the total harmonic distortion, the harmonic pollution in the power system will be reduced and the power quality will be increased. The proposed approach has been tested and validated on the matrix converter using Matlab/ simulink. The simulation results are shown to demonstrate the advantages of the proposed scheme.
\end{abstract}

Key words: Matrix converter, shunt matrix converter, shunt active filter, power quality, current harmonics, fuzzy logic controller

\section{INTRODUCTION}

Harmonic current pollution of 3-phase electrical power systems is becoming a serious problem due to the wide use of non-linear loads such as diode or thyristor rectifiers and a vast variety of power electronics based appliances (Hagh et al., 2009). Taking into account that the converter is supplied by a voltage source and usually feeds an inductive load, the input phases should never be short-circuited and the output currents should not be interrupted.

Recently, matrix converters are getting more attention in ac-ac power processing systems that require smaller size, higher power density and easier maintenance. Similarly, matrix converter also produces harmonics in the power system. As well known, the matrix converters have attractive characteristics such as sinusoidal input currents, a controlled input power factor, regeneration capability as well as the basic function to produce magnitude frequency controllable output voltages.

The performance of matrix converters is strictly dependent upon the Pulse-Width Modulation (PWM) strategy employed to control the bidirectional switches. Since, the introduction of the matrix converter various and numerous modulation methods have been developed to date (Li et al., 2009; Imayavaramban et al., 2004) (Fig. 1).

This method requires a formidable amount of complex calculations in the stage of implementation. Space Vector PWM (SVPWM) for a matrix converter explores a more systematic approach to understand the operation of the matrix converter (Yougui et al., 2008).

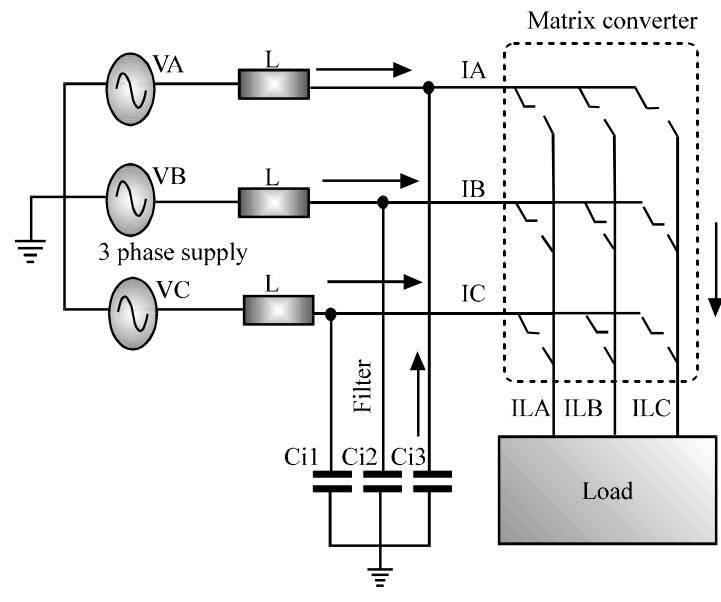

Fig. 1: General architecture of matrix converter

However, the SVPWM is far from intuitive and requires lookup tables with the previously initialized and stored switching patterns. Carrier based PWM may be the latest modulation strategy for matrix converters (Joshi et al., 2007). The carrier based PWM will employ the carrier and reference signals and can be implemented without complex calculations and lookup tables.

The above method however, involves proper offset voltages and discontinuous carrier signals which imply relatively indirect understanding of modulation processes. Also, the modulation algorithm suffers from additional complicated modification in order to get a maximum gain of 0.866 . Moreover, this method can not be applied to matrix converter topologies with a neutral connection between input and output neutrals.

Corresponding Author: P. JenoPaul, Noorul Islam University, Electrical and Electronics Engineering, Tamilnadu, India 


\section{POWER QUALITY ISSUES IN MATRIX CONVERTER}

Ideally, voltage is fed by a utility as a sinusoidal wave is having a magnitude and frequency given by national, international standards or system specifications with impedance of zero ohms at all frequencies. Generally, electrical power source is ideal and it can deviate in the following ways .Variations in the peak or RMS voltage are important to different types of equipment and load. When the RMS voltage goes beyond the nominal voltage by $10-80 \%$ for 0.5 cycles to $1 \mathrm{~min}$, the phenomena is called a swell (Fuchs and Mosoum, 2008). Sag is the opposite action: the RMS voltage goes below the rated voltage by $10-90 \%$ for 0.5 cycles to $1 \mathrm{~min}$ (Kusko and Thomsom, 1998). A variation in the wave shape is usually known as harmonics (De La Rosa, 2006). Matrix converter reflects the input voltage distortions to output voltage (Karacaand and Akkaya, 2010).

The passive input filters in matrix converter: Traditionally, passive LC filters have been used to eliminate the current harmonics and to improve the power factor. The input filter acts as an interface between the matrix converter and the $\mathrm{AC}$ mains. Its basic feature is to avoid significant changes of the input voltage of the converter during each PWM cycle and to prevent the unwanted harmonic currents from flowing into $\mathrm{AC}$ mains (Biela et al., 2009). Due to the discontinuous input currents, the matrix converter behaves as a source of current harmonics which are injected back into the $\mathrm{AC}$ mains (Zargari et al., 1993). Since, these current harmonics results in voltage distortions that affect the overall operation of the $\mathrm{AC}$ system, they should be reduced. The principal method of reducing the harmonics generated by static converters is provided by the input filter using reactive storage elements as shown in Fig. 2.

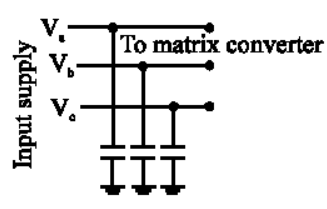

(a)

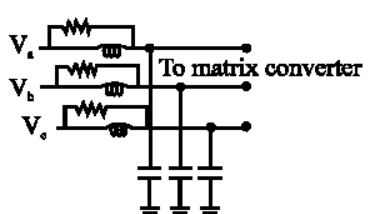

(b)

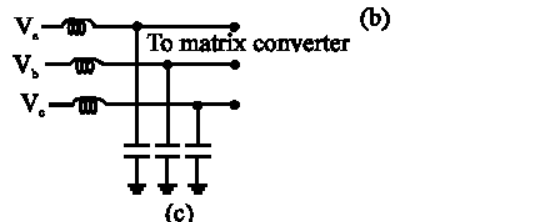

Fig. 2: Schematics representation of the basic input filter configuration (a) Capacitors connected in star (b) LC filter with damping resister (c) Second order LC filter
The problem of the input filter design for a matrix converter has been addressed in quite few researches (Huber and Borojevic, 1991; Wheeler et al., 1993) and looking at the literature, different configurations have been proposed for the matrix converter input filter (Vlatkovic et al., 1996; Casadei et al., 1997). Such differences are a consequence of different design criteria or at least differently weighted, different switching frequencies and different modulation strategies.

In order to meet the required attenuation requirement, the filter inductor size increases, these results in the overall increases with filter size. Moreover, the input filter output impedance, related to the total filter capacitor value is more difficult to control and leads to converter instability. As far as the matrix converter is concerned, a high displacement angle of the input line current due to the input filter capacitance component might be compensated by the matrix converter, setting as reference for the input current by a lagging displacement angle.

But in this way, the maximum voltage transfer ratio for the converter would be significantly reduced. Therefore, even for the matrix converter, the upper limit of the input filter capacitance is set by the minimum acceptable $\mathrm{AC}$ main power factor. Similarly, the control of the impedance interaction between the input filter and the voltage converter is necessary.

In general, the filters output impedance should be as low when compared to the converter input impedance. The filter output impedance can be reduced by increasing the filter capacitor size. Practically, the impedance interaction constraint determines the lower constraint on the filter capacitor value.

In addition to the this, proper filter pole damping is extremely important for achieving low filter output impedance for all frequencies and thus, overall system stability may be improved. In general, an optimized design of the matrix converter inpu filter is a quite difficult task since, it relies on a system level approach and in the light of the new coming harmonic and EMI reduction standards it can be somehow considered as an outstanding issue.

Active filter issues in matrix converter: Passive LC filters are bulky, load dependent and inflexible. They can also cause resonance problems to the system and provides either over-or under-compensation of harmonics whenever a load-change occurs (Prasad et al., 1991). In order to solve these problems, Active Power Filter (APF)'s have been reported (Moran et al., 1997) and considered as a possible solution for reducing current harmonics and the power factor will be improved. Figure 3 shows the basic compensation principle of the 3 phase shunt APF. It is designed to be connected in 


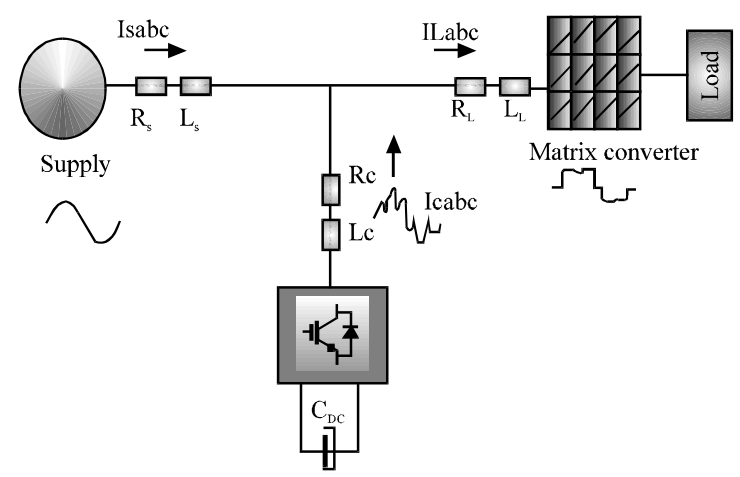

Fig. 3: General architecture of shunt active filter for matrix converter

parallel with the nonlinear load to detect its harmonic and reactive current and to inject a compensating current into the system. In the conventional p-q theory based control approach for the shunt APF, the compensation current references are generated based on the measurement of load currents. However, the current feedback from the Shunt Active Power Filter (SAPF) output is also required and therefore, minimum six control systems are desired in an unbalanced system.

The commonly used current control strategies are the hysteresis current control, the ramp comparison control methods (natural, asymmetrical or optimal PWM) associated with linear controllers and the predicted current control. The first method is very simple and easy to implement but has the disadvantage of an uncontrollable high switching frequency. This high frequency places great stress on the power transistors and induces significant switching losses. The 2 nd and 3 rd method allows the operation at a fixed switching frequency and is usually performed using software with the system parameters. In this case, the operating conditions must be known to achieve sufficient, accurate control.

\section{THE PROPOSED COMPENSATION SCHEME FOR MATRIX CONVERTER}

The most popular type of active filters is the shunt active filter. Shunt active filters can be single-phase or three-phase, voltage source or current source. Figure 4 shows the proposed compensation for matrix converter with a shunt active filter, source and load. When the filter is used to compensate the current harmonics produced by the matrix converter, active filter compensates the harmonic current of a matrix converter which produces harmonic current. In Fig. 4, $Z_{\mathrm{sA}}, Z_{\mathrm{sB}}, Z_{\mathrm{sC}}$ is impedances of the source and shunt passive filter, respectively. $\mathrm{I}_{\mathrm{lh}}, \mathrm{V}_{\mathrm{Lh}}$

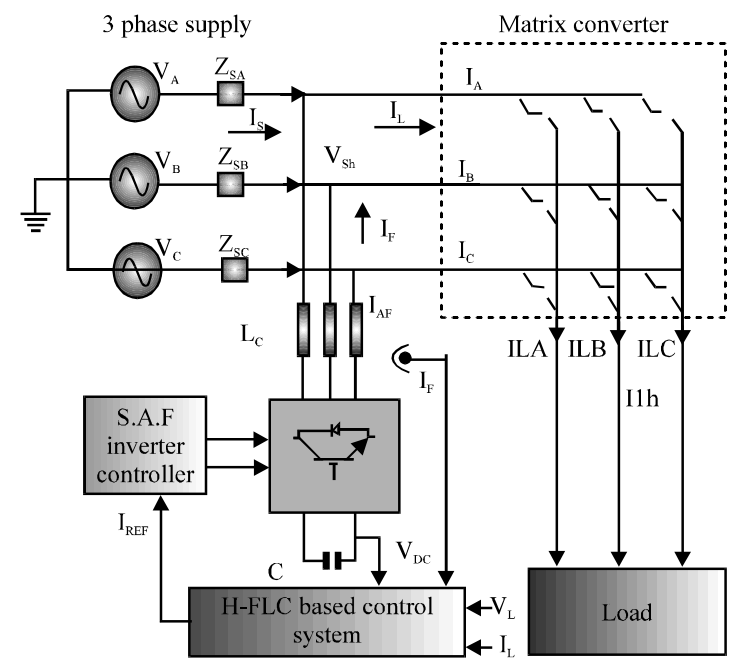

Fig. 4: Advanced compensation for matrix converter

and $\mathrm{V}_{\text {sh }}$ are the current harmonic of the load, voltage harmonic of the load and source harmonics, respectively. $I_{A F}$ is the current of the shunt active filter. The control system design of the shunt active power filter for matrix converter cancel the harmonics in the supply current is shown in Fig 4. Shunt active filters are used to compensate current harmonics of nonlinear loads to perform reactive power compensation and to balance imbalance currents. The matrix converter is considered as one type of load i.e., current-source type of Harmonic sources. Power electronics converters are a common and typical source of harmonic currents. The distortion of the current waveform, i.e., the generation of harmonics, results from the switching operation. Because the harmonic current contents and characteristic are less dependent upon the $\mathrm{AC}$ side, this type of harmonic source behaves like a current source. Therefore, they are called current-source type of harmonic source (or harmonic current source) and represented as a current source. A shunt active filter is to be placed in parallel with a load (matrix converter) to detect the harmonic current of the load and to inject a harmonic current with the same amplitude of that of the load into the AC system.

Analysis of proposed shunt active filter for matrix converter: In order to have generality, the harmonic current source is represented as Norton's equivalent circuit. A pure current-source type of harmonic source is a special case of the Norton's equivalent with $Z_{L}$. Figure 5 shows the basic principle of a shunt active filter compensating for a harmonic current source where the harmonic source is represented as Norton's equivalent, $Z_{s}$ is the source (line) impedance, $I_{L}$ is the equivalent 


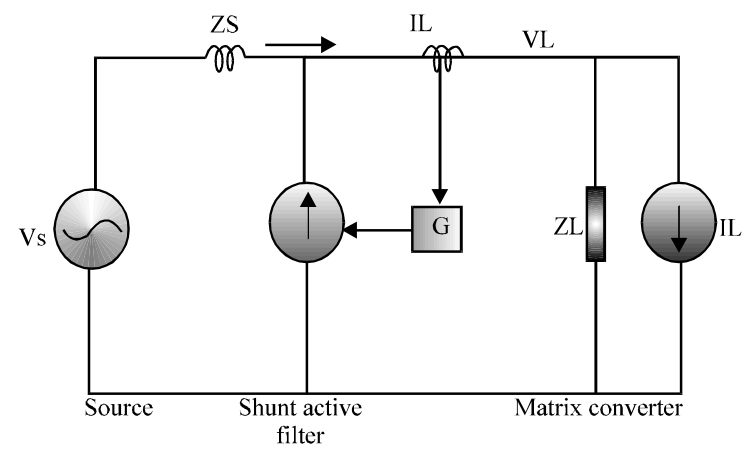

Fig. 5: Principle of shunt active filter for matix converter

harmonic current source, $Z_{\mathrm{L}}$ is the equivalent impedance on the input side of matrix converter which may include passive filters and power-factor correction capacitors and $\mathrm{G}$ is the equivalent transfer function of the active filter including the detection circuit of harmonics and the delay of the control circuit.

In general, $G$ has the function of notching the fundamental component that is $\mathrm{G}_{\mathrm{h}}=0$ at the fundamental and $|\mathrm{G}|_{\mathrm{h}}=1$ for harmonics. In the following analysis, all equations are represented in per unit. From Fig. 5, the following equations are obtained:

$$
\begin{gathered}
I_{C}=G_{L} \\
I_{S}=\frac{Z_{L}}{Z_{S}+\frac{Z_{L}}{1-G}} \cdot I_{L O}+\frac{V_{S}}{Z_{S}+\frac{Z_{L}}{1-G}} \\
I_{L}=\frac{\frac{Z_{L}}{1-G}}{Z_{S}+\frac{Z_{L}}{1-G}} \cdot I_{L O}+\frac{1}{1-G} \cdot \frac{V_{S}}{Z_{S}+\frac{Z_{L}}{1-G}}
\end{gathered}
$$

Focusing on harmonic:

$$
\begin{gathered}
\left.\left|\frac{\mathrm{Z}_{\mathrm{L}}}{1-\mathrm{G}}\right|_{\mathrm{h}}\right\rangle\left|\mathrm{Z}_{\mathrm{S}}\right|_{\mathrm{h}} \\
\mathrm{I}_{\mathrm{C}}=\mathrm{I}_{\mathrm{Lh}} \\
\mathrm{I}_{\mathrm{Lh}}=\mathrm{I}_{\mathrm{LOh}}+\frac{\mathrm{V}_{\mathrm{Sh}}}{\mathrm{Z}_{\mathrm{L}}}
\end{gathered}
$$

Where, the subscripts $h$ and $f$, represent the harmonic components and the fundamental components, respectively. Modulus represents the magnitude of a transfer function. $G$ can be predesigned and determined by the active filter while $Z_{s}$ and $Z_{L}$ are determined by the

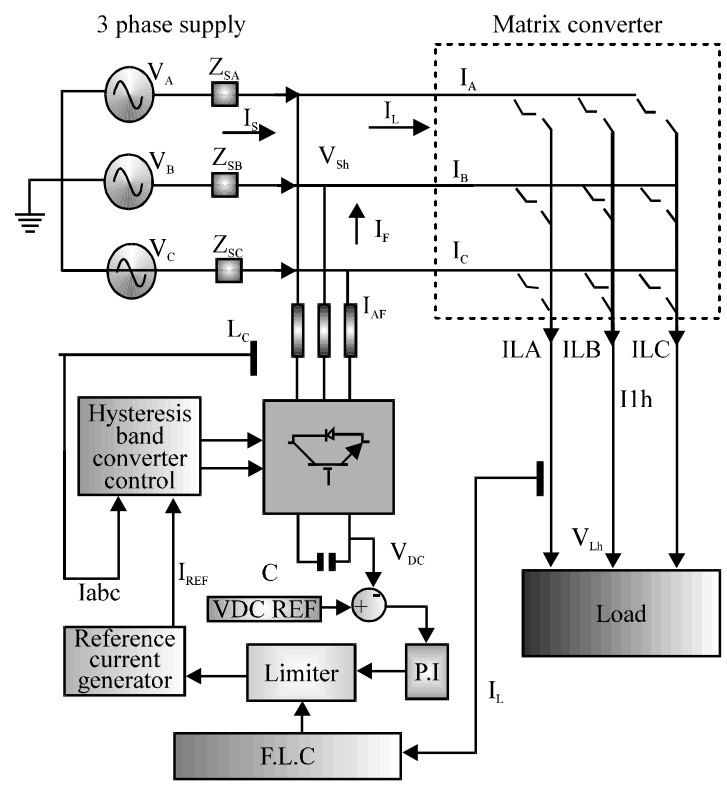

Fig. 6: Proposed controller based shunt active filter for matrix converter

system, i.e., parameters of the ac source and the load side of the matrix converter. A shunt active filter senses the load current and injects a current into the system to compensate current harmonics or reactive load. In this study, a shunt filter was used to compensate the current harmonics of matrix converter here, the shunt active filter acts as a current source. The sum of its current and load current is the total current that flows through the source. Therefore, controlling the output current of the active filter can control the source current.

Proposed intelligent control system of shunt active filter: A Fuzzy Logic Controller (FLC) is designed to take over the work of variable limiter based on look-up table. The new topology of APF with Hysteresis FLC (H-FLC) based limiter is shown in Fig. 6. An adaptive hysteresis band current control PWM technique can be programmed as a function of the active filter and supply parameters to minimize the influence of current distortions on the modulated waveform.

The width of the Hysteresis Band (HB) can be modulated at different points of the fundamental frequency of the cycle to control the PWM switching pattern of the inverter. The limiter value varies with change in load current, however the nature of variation is highly non-linear and it is difficult to relate it by mathematical expression. Also in practice, the nature of input power to load is not pure sinusoidal rather stochastic in nature. Hence, mathematical modeling of variable saturation value may not be able to fully compensate the effect of harmonics. Fuzzy logic is an alternative approach to handle this type of problem which 
has become more popular during past four decades due to its advantages of robustness against parameter variation, popularity, customization, etc. When system is too complex or too poorly understood to be described in precise mathematical terms, fuzzy modeling provides the ability to linguistically specify approximate relationships between the input and desired output.

The relationships are represented by a set of fuzzy if then rules in which the antecedent is an approximate representation of the state of the system and the consequent provides a range of potential responses. In this study, FLC is used to regulate the limiter value according to load current. The range of operating current and particular band of operating current is one of the important design factors of fuzzy controller.

The proposed hysteresis FLC compensates the harmonic current for any load current variation between 1.5 and $80 \mathrm{~A}$. The block diagram representation of fuzzy logic controller is shown in Fig. 6 which contains the following design parameters: number and type of membership functions for input and output variables, rule base, defuzzification method.

Membership functions for input and output variable: Computational efficiency, memory requirement and computational time are the few important aspects of evolutionary computational methods. The number and type of Membership Function (MF) decides the computational efficiency of a FLC. The shape of fuzzy set affects how well a fuzzy system of if then rules approximate a function.

Triangles have been the most popular if part set shape for approximating non-linear function. Studies reported in have shown that triangular membership function is most economical in the sense of above said parameters. Here, the membership functions are chosen to be triangular (Fig. 7) because the parametric functional description of triangular $\mathrm{MF}$ is most economic one. The triangular membership functions have been frequently used in many applications of fuzzy sets including fuzzy controllers, fuzzy models and classification.

Triangular membership functions are preferred because of their striking simplicity, solid theoretical basis and ease of computation, since they are symmetrical and have zero value at some point away from their center. Pedrycz has carried out a detailed study legitimizing the

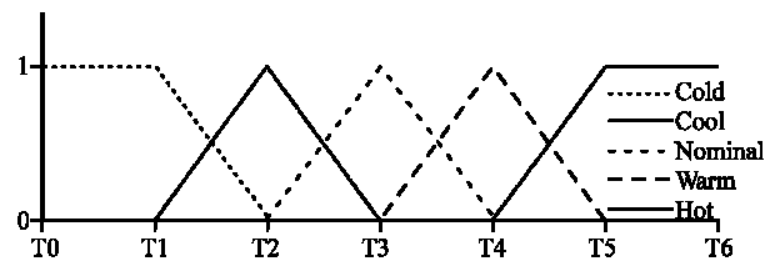

Fig. 7: Example of fuzzy membership function use of the triangular membership function. In the present case, the choice of MF does not much affect the performance of system.

However, to reduce the complexity and to involve minimum computational memory, the triangular MFs are chosen. For this research, 9 unequally spaced triangular membership functions have been chosen for representing each linguistic variables, viz., Z, VS, S, SS, SM, M, MD, H and $\mathrm{VH}$. The reason for unequal spacing is to cover a band of load current with high accuracy. The number of linguistic variables is directly related to the accuracy of approximating function and plays an important role for approximating the non-linear input-output mapping. The number of linguistic variable increases and the output of fuzzy controller becomes a linear function of the input. In the present case, a non-linear mapping of input-output is performed via fuzzy logic.

In order to trade-off between accuracy and complexity, through rigorous simulation studies it has been found that nine MFs are sufficient to produce desired results in required band. Reducing the number of MFs will produce improper results at some band while increasing the number of MFs will produce a delay due to more computational steps required.

The linguistic variables are defined by ${ }^{\sim} \mathrm{M}=(\mathrm{a}, \mathrm{b}, \mathrm{c})$ where $\mathrm{a}, \mathrm{b}, \mathrm{c}$ are starting, middle point with unity membership grade and end points, respectively. Again, each fuzzy set is $50 \%$ overlapped with neighbor. In present case, the function of fuzzy logic is to map a nonlinear input-output function. Thus, the number of rules is directly related with number of $\mathrm{MF}$ for input and output. Hence, in the present case 9 rules are made.

The weighted factor of FLC is an important factor for producing accurate output. Since, the antecedent part of rules are chosen as linear combination of input, the weighted factors are also linear and of zero order.

Inference rule: The supply voltage wave, vs(t) and main current reference slope, dis */dt can be selected as input variables to the fuzzy controller and the hysteresis band Hysteresis Band Magnitude (HB) as an outputvariable. The following step is used to determine the set of linguistic values associated with each variable. Each input variable is transformed into a linguistic size with 5 fuzzy subsets:

Table 1: Inference rules (supply voltage wave, $\mathrm{V}_{\mathrm{s}}$ and main current reference

\begin{tabular}{llllll}
\multicolumn{7}{c}{ slope, $\left.\mathrm{di}^{*} / \mathrm{dt}\right)$} & & & & \\
\hline & NL & NM & EZ & PM & PL \\
\hline NL & PL & PM & PM & PM & PL \\
NM & PL & PM & PS & PM & PL \\
EZ & PVL & PM & PS & PM & PVL \\
PM & PL & PMM & PS & PM & PL \\
PL & PL & PM & PM & PM & PL \\
\hline
\end{tabular}


$\mathrm{PL}=$ Positive large

$\mathrm{PM}=$ Positive medium

PS $=$ Positive small

$\mathrm{EZ}=$ Zero

$\mathrm{NL}=$ Negative large

$\mathrm{NM}=$ Negative medium

NS $=$ Negative small

For the output variable:

$\mathrm{HB}, \mathrm{PVS}=$ Positive very small

PS $\quad=$ Positive small

$\mathrm{PM}=$ Medium positive

$\mathrm{PL} \quad=$ Positive large

PVL = Positive very large

The membership functions of the input and output variables and the resulting inference rules are shown in Table 1.

\section{SIMULATION RESULT}

Simulation is carried out on Matlab/simulink software and the use of the shunt active filter for matrix converter is evaluated. The simulated SAPF system parameters are shown in Table 2. In the simulation studies, the result are specified before and after SAPF system is operated. In Fig. 8 the simulations of the matrix converter operates without input capacitor is shown. Here, the line voltage is
$440 \mathrm{v}$; the supply current is 200 Amperes. In this simulation, the input current wave shape is nonsinusoidal and it contains harmonics. The simulation time start from $0.02-0.085 \mathrm{sec}$. Consider the simulation time, $0.025-0.045 \mathrm{sec}$ is the one cycle of the current wave form. Here, the wave shape of this current is non-sinusoidal and it contains harmonics. In the Fig. 9, the simulation of the matrix converter operated with input capacitor is shown. The capacitor value is shown in Table 2. The input current wave form is also non-sinusoidal. The harmonics are not effectively eliminated by the fixed capacitor bank and the input current wave farm obtained is non sinusoidal and is shown in Fig. 9. Consider the simulation time $0.025-0.045 \mathrm{sec}$, the current wave form is nonsinusoidal and it contain harmonics. Figure 10 shows the proposed shunt active power filter scheme that compensates the line current wave shape effectively when

Table 2: SAPF experimental and simulation parameters

\begin{tabular}{lll} 
Categories & Parameters & Values \\
\hline Source & Voltage $\left(\mathrm{V}_{\text {Sabc }}\right)$ & $440 \mathrm{~V}_{\text {Rms }}$ \\
& Frequency $(\mathrm{F})$ & $50 \mathrm{~Hz}$ \\
Load & 3 phase line inductance $\left(\mathrm{L}_{\mathrm{Labc}}\right)$ & $1 \mathrm{mH}$ \\
& 3 phase load resistance $\left(\mathrm{R}_{\mathrm{L}}\right)$ & $2 \Omega$ \\
DC link & Voltage $\left(\mathrm{V}_{\mathrm{dc}}\right)$ & $1200 \mathrm{~V}$ \\
& Capacitor $\left(\mathrm{C}_{1}, \mathrm{c}_{2}\right)$ & $2200 \mu \mathrm{F}$ \\
SAPF & Ac line inductance $\left(\mathrm{L}_{\mathrm{Cabc}}\right)$ & $0.5 \mathrm{mH}$ \\
& Filter resistance $\left(\mathrm{R}_{\mathrm{Cabc}}\right)$ & $4.7 \Omega$ \\
& Filter capacitor $\left(\mathrm{C}_{\mathrm{Cabc}}\right)$ & $100 \mu \mathrm{F}$ \\
& Switching frequency $\left(\mathrm{F}_{\text {pum }}\right)$ & $20 \mathrm{kHz}$ \\
\hline
\end{tabular}

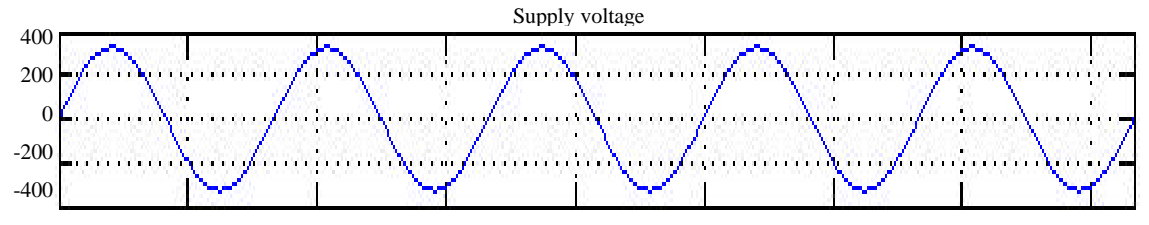

Supply current

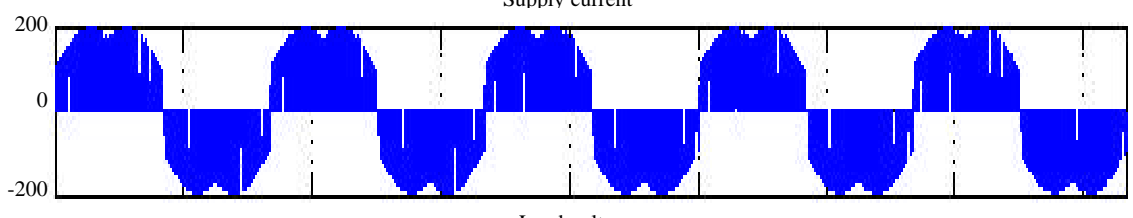

Load voltage

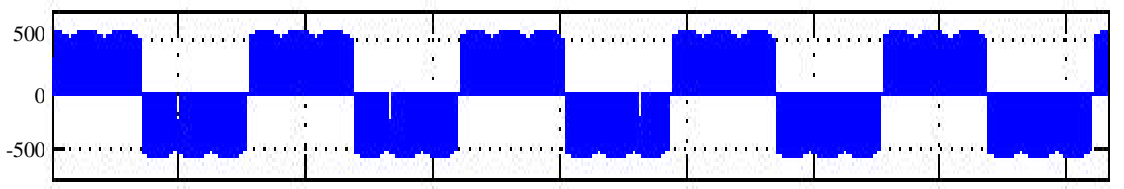

Load current

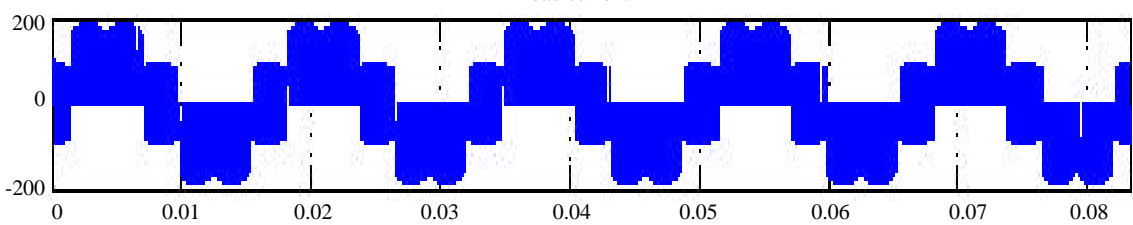

Fig. 8: System voltage $\left(V_{s}\right)$ source current $\left(I_{s}\right)$ load voltage $\left(V_{L}\right)$ and load current $\left(I_{L}\right)$ without filter 

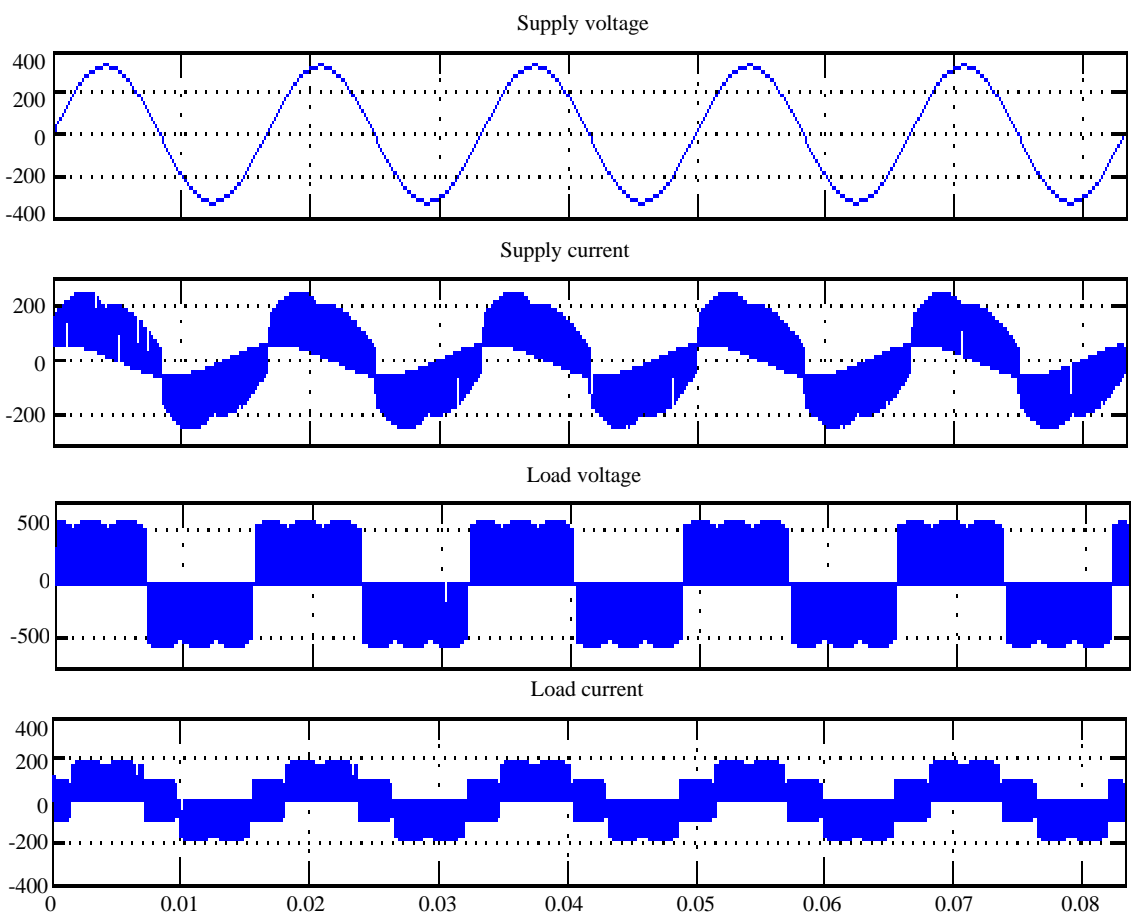

Fig. 9: System voltage $\left(V_{s}\right)$ source current $\left(I_{s}\right)$ load voltage $\left(V_{L}\right)$ and load current $\left(I_{L}\right)$ with fixed filter
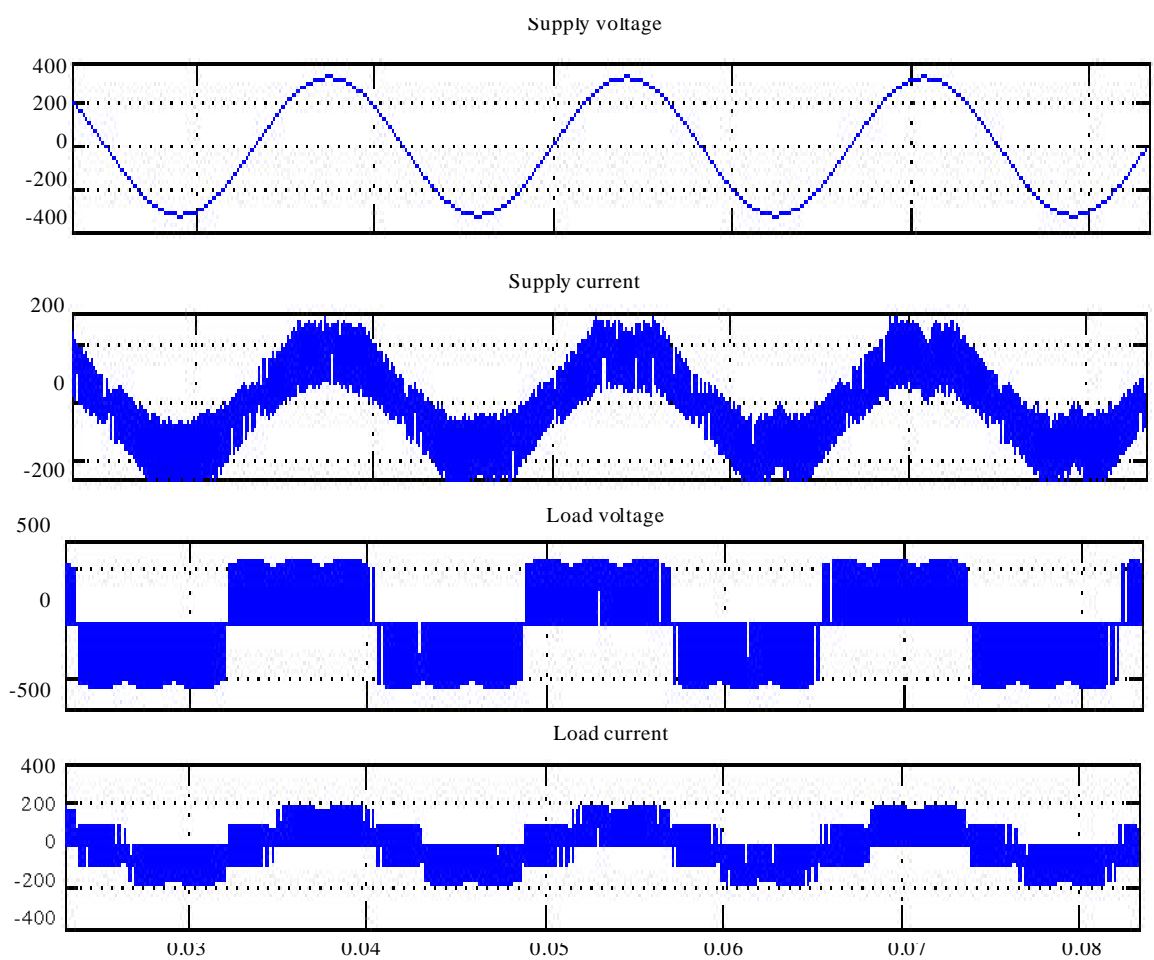

Fig. 10: System voltage $\left(V_{s}\right)$ source current $\left(I_{s}\right)$ load voltage $\left(V_{L}\right)$ and load current $\left(\mathrm{I}_{\mathrm{L}}\right)$ when the existing shunt active filter is turned on

compared to the existing system, effectively. The total simulation time is $0.02-0.085 \mathrm{sec}$. In this simulation, the current waveform is almost sinusoidal. Here, Load frequency is $60 \mathrm{~Hz}$. Figure 11 shows the proposed H-FLC based shunt active power filter scheme that compensates the line current wave shape effectively when compared to 

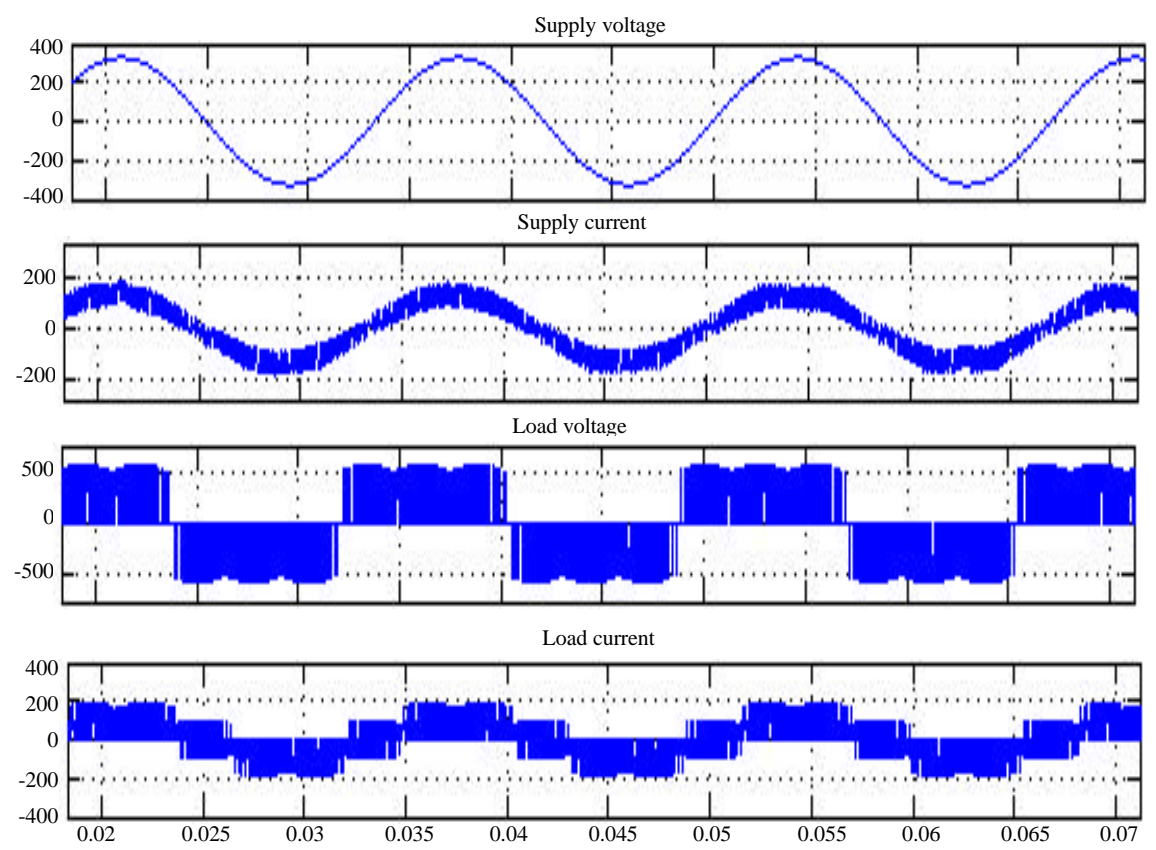

Fig. 11: System voltage $\left(V_{s}\right)$ source current $\left(\mathrm{I}_{s}\right)$ load voltage $\left(\mathrm{V}_{\mathrm{L}}\right)$ and load current $\left(\mathrm{I}_{\mathrm{L}}\right)$ when the H-FLC based controller based shunt active filter is turned on

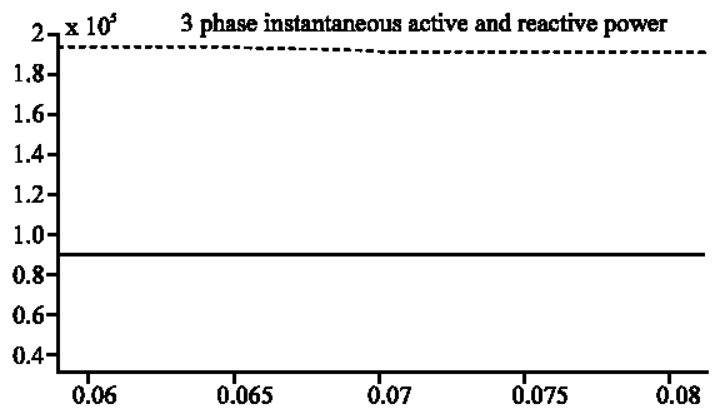

Fig. 12: Real and reactive power existing method controller

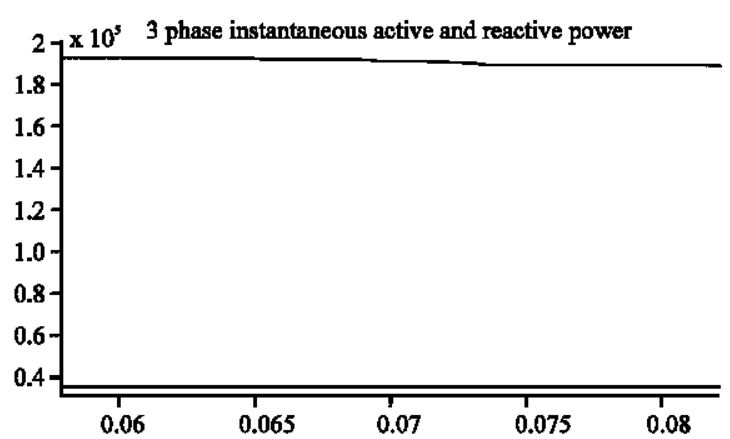

Fig. 13: Real and reavtive power with proposed controller compensation

the existing instantaneous reactive control $(\alpha-\beta-0)$ based controller effectively as shown in the simulation

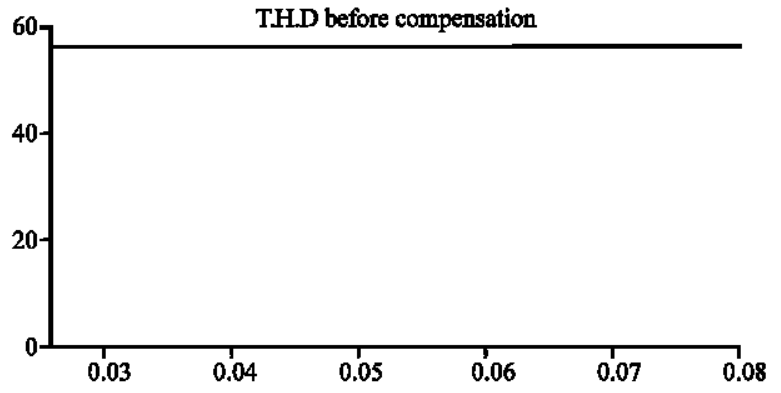

Fig. 14: Total harmonic distortion existing method

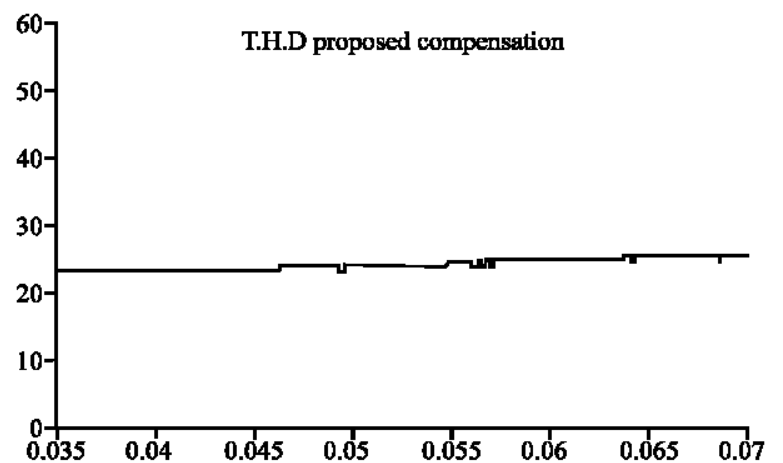

Fig. 15: Total harmonic distortion proposed system

results. The total simulation time is $0.02-0.07 \mathrm{sec}$. In this simulation, the current waveform is almost sinusoidal. Figure 12 shows the input power factor without 
compensation. Here, the reactive power is lagging. In Fig. 12, the shunt active filters not only compensate the current harmonics but also it compensates the reactive power as shown in the simulation result shown in Fig. 13 the reactive power factor is almost unity. Figure 14 shows that the supply current harmonics are $60.05 \%$. After the proposed shunt active filter is implemented, the supply current harmonics is reduced $25 \%$ as shown in Fig. 15. Power quality is maintained by using the shunt active filter.

\section{CONCLUSION}

This study has validated a simple control approach with a parallel active power filter based on the method of hysteresis fuzzy logic controller. Simulations results show the need for regulation of the DC voltage of the active filter and control of the current at its exit point. The conventional control approaches has not given good performance and it results in slow response. With the fuzzy hysteresis current control method, the band can be easily implemented with fuzzy logic to keep the modulation frequency nearly constant and achieves good quality filtering. Application of fuzzy logic in the control loops enables to choose optimal values of the inductance of decoupling and the storage capacity. With these types of controls, the active filter can be adapted easily to other more severe constraints such as unbalanced conditions. The proposed strategy can restrict up to $25 \%$ of lower, high harmonic components. When proposed system is operated in matrix converter, the supply harmonics are removed effectively compared to the existing controller. The modification of this proposed methodology has given considerably good simulation results as compared to the conventional harmonic control method. The proposed method is validated and the simulation results are obtained through mat lab/simulink software.

\section{REFERENCES}

Biela, J., A. Wirthmueller, R. Waespe, M.L. Heldwein, K. Ragg1 and J.W. Kolar, 2009. Passive and active hybrid integrated EMI filters. IEEE Trans. Power Electr., 24: 1340-1349.

Casadei, D., P. Nielsen, G. Serra and A. Tani, 1997. Theoretical and experimental analysis of SVMcontrolled matrix converters under unbalanced supply conditions. Electromotion J., 4: 28-37.

De la Rosa, F.C., 2006. Harmonics and Power Systems. Taylor and Francis Group, New York, pp: 184.

Fuchs, E. and M.A.S. Mosoum, 2008. Power Quality in Power Systems and Electrical Machines. Academic Press, England, UK., pp: 664.
Hagh, M.T., H. Taghizadeh and K. Razipp, 2009. Harmonic minimization in multilevel inverters using modified species-based particle swarm optimization. IEE Trans. Power Electr., 24: 2259-2267.

Huber, L. and D. Borojevic, 1991. Input filter design of forced commutated cycloconverters. Proceedings of the 6th Mediterranean Electrotechnical Technical Conference, May 22-24, Ljubljana, Slovenia, pp: 1356-1359.

Imayavaramban, M., K. Latha and G. Uma, 2004. Analysis of different schemes of matrix converter with maximum voltage conversion ratio. Proceedings of the 12th IEEE Mediterranean Electrotechnical Conference, May 12-15, India, pp: 1137-1140.

Joshi, R.R., R.A. Gupta and A.K. Wadhwani, 2007. Optimal intelligent controller for matrix converter induction motor drive system. Iranian J. Electrical Comput. Eng., 6: 19-26.

Karacaand, H. and R. Akkaya, 2010. Modelling and simulation of matrix converter under distorted input voltage conditions. Simulation Modell. Practice Theory, 19: 673-684.

Kusko, A. and M.T. Thomsom, 1998. Power Quality in Electrical System. McGraw Hill, NewYark, pp: 32.

Li, Y., N.S. Choi and B.M. Han, 2009. DDPWM based control of matrix converters. J. Power Electr., 9: $535-543$.

Moran, L.A., L. Fernandez, J.W. Dixon and R. Wallace, 1997. A simple and low-cost control strategy for active power filters connected in cascade. IEEE Trans. Ind. Electr., 44: 621-629.

Prasad, A.R., P.D. Ziogas and S. Manias, 1991. An active power factor correction technique for three-phase diode rectifiers. IEEE Trans. Power Electr., 6: 83-92.

Vlatkovic, V., D. Borojevic and F.C. Lee, 1996. Input filter design for power factor correction circuits. IEEE Trans. Power Electr., 11: 199-205.

Wheeler, P.W., H. Zhang and D.A. Grant, 1993. A theoretical and practical investigation of switching frequency harmonics in a matrix converter. Proceedings of the Universities Power Electronics Conference, September 1993, Stafforf, UK., pp: 502-505.

Yougui, G., Z. Jianlin and D. Cheng, 2008. Three modulation modes of SVM for AC-AC matrix converter. Proceedings of the IEEE Conference on Robotics, Automation and Mechatronics, Sept. 21-24, Chengdu, pp: 382-387.

Zargari, N.R., G. Joos and P.D. Ziogas, 1993. Input filter design for pwm current-source rectifiers. Proceedings of the Applied Power Electronics Conference and Exposition, March 7-11, San Diego, CA USA., pp: 824-830. 